\title{
Representações discursivas da Geografia Física em livros didáticos de Geografia
}

\author{
DisCURSIVE REPRESENTATIONS OF PHYSICAL GEOGRAPHY IN GEOGRAPHY TEXTBOOKS
}

\author{
Darlan da Concelção Neves ${ }^{1}$ \\ Alfredo Borges de Campos ${ }^{2}$ \\ 1- Mestre pelo Progr. Pós-Grad. Ensino eHistória deClências da Terra, Inst. Geoc., Univ. Est. Campinas, Campinas, SP. \\ 2 - Dcente do Progr. Pós-Grad. Ensino eHistória deCiências da Terra, Inst. Geoc., Univ. Est. Campinas, Campinas, SP. Brasil. \\ E-MAILS: DNEVES1987@gmaIl.com, ALFRED0.BORGES.CAMPOS@gmall.com
}

Abstract: The present paper discusses the discursive representations of contents of Physical Geography in Geography textbooks. For methodological purposes, the authors used the Critical Discourse Analysis, which considers the text a discursive work and a social practice. It was found that the contents of Physical Geography exhibit traces of intertextuality and interdiscursivity as active means to teach natural phenomena, in order to mobilize the prior knowledge of readers.

\author{
Manuscrito: \\ Recebido: 22/11/2017 \\ Correção: 24/10/2018 \\ Aceito: 04/01/2019
}

Citação: Neves D. da C., De-Campos A. B. 2019. Representações discursivas da Geografia Física em livros didáticos de Geografia. Terræ Didatica, 15, 1-11, e019014. doi: 10.20396/ td.v15i0.8650328.

Palavras-chave: Discurso, ensino de geografia, eventos naturais.

\section{Introdução}

Buscamos investigar as formas pelas quais os discursos de Natureza figuram nos textos de 1 livro didático de Geografia. Para tanto, nos debruçamos a fim de identificar a interdiscursividade que atesta como base material para a construção de sentidos. A forma pela qual cada enunciado aparece em determinados contextos não é ao acaso, pois há condições de produção específicas de discurso que possibilitam a sua enunciação (Maingueneau, 2005).

Apesar da incorporação das novas tecnologias no ambiente escolar, é evidente que muitos alunos e alunas, dada cada realidade, têm o livro didático de Geografia como fonte de consulta principal e imediata, seja por falta de condições de acesso a outras fontes, ou pela própria estrutura da escola; a falta de bibliotecas estruturadas com material consultivo em algumas escolas e/ou espaços para estudos extraclasse, computadores que não funcionam, bem como a deficiência no fornecimento da conexão da internet fomentam o exacerbado uso desse recurso pelo aluno.

Há que se considerar também que esse mesmo recurso tem norteado a prática docente, seja pela incompletude da formação do professor ou pela necessidade de formação continuada, além das condições materiais (ambiente escolar, programas educacionais de governo e políticas públicas) para o desenvolvimento da prática docente. Embora seja o livro didático de Geografia um instrumento ainda válido nas salas de aula, há quem o rejeita. Entendemos que este material deve ser utilizado como material complementar. Como mais um recurso em meio a tantos outros de que o professor dispõe, para realizar o andamento das atividades pedagógicas.

No contexto da educação brasileira o livro didático assumiu papel preponderante, segundo os discursos oficiais, para a garantia da qualidade de ensino. Cassiano (2007) afirma que, com a criação da Programa Nacional do Livro Didático - PNLD, na década de 1980, as políticas públicas educacionais concentravam esforços conjunturais para manter por meio do livro, o discurso de projeto de educação e de sociedade que se almejava. Não obstante, o livro didático recebera críticas de estudiosos por entenderem que este material não deveria conter conteúdo ideológico e generalista.

Segundo Tonini (2011) os livros didáticos de Geografia têm passado por significativas modificações. Esta autora afirma que até meados do século $\mathrm{XX}$, este material escolar estava dentro da perspectiva tradicional, com o texto centralizando toda a leitura. A partir das mudanças sociais e desenvolvimento dos meios midiáticos, o livro didático vem se 
adequando para tornar a sua leitura mais dinâmica e atrativa, com a inserção de imagens, gráficos, mapas e informações diversas.

Segundo a autora, a incorporação dessa nova forma de pensar e produzir este recurso pedagógico está atrelada às questões sociais atuais, como por exemplo, a inserção da tecnologia nas atividades escolares, que tem buscado novas maneiras de ressignificar a informação, o conhecimento, a realidade e a leitura.

É por meio do livro didático que a sociedade, ou uma parcela dela, estabelece o que deve ser lembrado e o que é realmente importante conhecermos em determinado período. Essas questões estão vinculadas às finalidades do ensino, as quais estão representadas nos livros didáticos, o que lhes atribui um caráter de difusor de determinadas visões de mundo (Albuquerque, 2011, 59).

A autora argumenta que muitos professores ao utilizarem o livro didático como principal instrumento de trabalho, o legitimam como sendo o próprio currículo, portanto orientador da prática pedagógica, da ordem dos conteúdos, bem como sua posição teórico-política. O livro didático é produtor de sentidos na sala de aula, tanto o professor quanto o aluno, que fazem uso desse material, o concebe como portador de conhecimentos legitimados necessários para a formação. E como objeto cultural seleciona parte da realidade que deve ser transmitida, representada e aprendida.

Como discurso, o livro didático estabelece diálogo entre autor(a) do livro e leitor/a (aluno/a). Por meio de seu uso, há uma relação dialógica de construção de sentidos que, segundo Bakhtin (2009) são frutos de uma relação conflituosa entre sujeitos, de tempos diferentes, sobre o mesmo objeto e os conteúdos abordados. "O dialogismo diz respeito às relações que se estabelecem entre o eu e o outro nos processos discursivos instaurados historicamente pelos sujeitos, que, por sua vez, se instauram e são instaurados por esses discursos" (Brait, 2005, p. 95). No caso desta pesquisa, são os enunciados da Geografia Física, tramados no livro didático, que vão traçar o fio condutor dessa relação dialógica entre autor e leitor.

O discurso entorno da estrutura conceitual de natureza depende de inúmeros fatores relacionados com os autores dos livros didáticos de Geografia: a cultura, os objetivos políticos e econômicos, a postura filosófica e a finalidade do próprio ensino de Geografia. Essa estrutura segue uma lógica, um padrão metodológico, uma forma coerente com o próprio pensamento dos autores e; assim, apontam para uma direção conceitual que seguem por toda a obra didática por meio da própria concretização do discurso que é a escrita (Barbosa, 2006, p. 240).

No trabalho de Barbosa (2006) constatou-se a historicidade da produção discursiva em livros didáticos. Essa historicidade está representada nos discursos geográficos e filosóficos. O autor vislumbrou a interdiscursividade presente nesses materiais e identificou que a história e a tradição são elementos concorrentes que põem em funcionamento o que deve e como ser dito a respeito da natureza. Esses dois elementos respaldam a regularidade dos enunciados. É sobre esta interdiscursividade histórica que investigamos e apresentamos os resultados nas próximas páginas.

\section{Materiais e Métodos}

Para identificação de como a natureza está representada discursivamente em livros didáticos de Geografia, optamos por seguir duas orientações metodológicas: a) o discurso como tema (Natureza) proposto por Maingueneau (2013) e a partir deste tema nos debruçarmos sobre os enunciados que constituem os sentidos sobre a Natureza em textos didáticos; b) a investigação dos sentidos do discurso com base na Análise de Discurso Crítica proposta por Fairclough (2016).

A perspectiva crítica de investigação discursiva apresenta em suas considerações o discurso como prática social. Seguindo o pensamento de Fairclough (2016), há uma relação dialética entre discurso e estrutura social, ou melhor, entre prática social e a estrutura social, sendo a estrutura social tanto condição como efeito da prática social. De acordo com esta abordagem, o discurso pode ser moldado ou constrangido a depender de onde é enunciado; assim, as instituições particulares, as relações sociais, a classe social e outras situações de práticas linguageiras, atuam a partir de suas convenções e normas ou prática de natureza não discursiva que podem operar na mudança e natureza do discurso.

\section{Resultados e Discussão}

Iniciamos o movimento de investigação a partir do livro 1 da coletânea "Geografia: espaço e vivência” de Boligian \& Alves (2013), que faz parte da coletânea de três livros que compõem o corpus de uma pesquisa mais ampla. Os textos selecionados e postos no quadro 1 estão localizados na Unidade 
II do livro distribuídos nos capítulos 3, 4, 5, 6, 7, $8,9,10,11$ e parte do 12 , como mostra a Tabela 1 .

Procederemos à descrição em alguns momentos fora da ordem de como os textos se apresentam no livro didático para melhor compor os nossos argumentos. Pela busca dos nexos discursivos presentes nos textos, optamos por apresentar as categorias analíticas da Análise de Discurso Crítica "intertextualidade" e "interdiscursividade", que serão discutidas adiante, para identificar os sentidos de natureza que são validados.

A Unidade II, que tem como título "A dinâmica da natureza e as paisagens terrestres", apresenta o funcionamento dos processos naturais, nos capítulos subsequentes, por meio dos quais alguns elementos dos sistemas naturais recebem destaque: a água, as rochas, o clima. Os conteúdos versam sobre esses três temas gerais, a partir das esferas terrestres, quais sejam a biosfera, a hidrosfera, a atmosfera e a litosfera.

$\mathrm{Na}$ apresentação da Unidade II há várias maneiras pelas quais se representa a natureza: "instável", "imprevisível", "único", "casa”. A palavra "único" atesta seu caráter singular de organismo como um todo vivo, em movimento e que interage com seus elementos. Já a utilização do léxico "casa”, como metáfora, traz o efeito de sentido de proximidade, de lar, que contrasta com a ideia de planeta instável e imprevisível.

A polifonia é utilizada para a sua identificação, de movimento que o planeta e, consequentemente, a natureza possui, foram utilizados os dois primeiros léxicos qualitativos supracitados. Segundo Bakhtin (2009) a polifonia é a presença de muitas vozes em um discurso. Para Maingueneau (2005) o interdiscurso releva as condições de produção do universo discursivo que põe as vozes validadas para funcionar o discurso.

Há em todos os textos uma preocupação de deixar claro que a natureza, o planeta Terra, é composta por elementos que interagem entre si e que, ao longo do tempo, produzem distintas paisagens na superfície terrestre. Isso evidencia o posicionamento teórico-discursivo no qual os locutores se filiam para apresentar a natureza por meio da Teoria Geral dos Sistemas, em primeiro plano como suporte epistêmico, e da Teoria dos Geossistemas como posicionamento teórico-metodológico: a Terra que pode ser subdividida em subsistemas físicos, possui um caráter de movimento constante pelas interrelações desses subsistemas, a partir de
Tabela 1. Títulos dos textos analisados do livro didático, coletânea Geografia - espaço e vivência. Fonte: Boligian \& Alves (2013)

\begin{tabular}{|c|c|}
\hline Capítulo & Tema/item \\
\hline $\begin{array}{l}\text { 3: O tempo } \\
\text { da natureza e } \\
\text { as marcas das } \\
\text { paisagens }\end{array}$ & $\begin{array}{l}\text { - O estudo científico das marcas } \\
\text { das paisagens. }\end{array}$ \\
\hline $\begin{array}{l}\text { 4: A biosfera: } \\
\text { interação e } \\
\text { dinâmica do } \\
\text { planeta. }\end{array}$ & $\begin{array}{l}\text { - } \\
\text { - } \quad \text { A forma e os movimentos da } \\
\text { Terra } \\
\text { - } \\
\text { Reflexão e absorção da energia } \\
\text { solar }\end{array}$ \\
\hline $\begin{array}{l}\text { 5: A dinâmica } \\
\text { atmosférica }\end{array}$ & $\begin{array}{ll}\text { - } & \text { A troposfera e a radiação solar } \\
\text { - } & \text { A importância da radiação solar } \\
& \text { As zonas de alta e baixa pressão } \\
& \text { atmosférica } \\
\text { - } & \text { A circulação atmosférica global } \\
\text { - } & \text { As massas de ar e as frentes de } \\
& \text { transição }\end{array}$ \\
\hline $\begin{array}{l}\text { 6: Tempo e } \\
\text { clima: qual é a } \\
\text { diferença? }\end{array}$ & $\begin{array}{l}\text { - } \quad \text { Previsão do tempo meteorológico } \\
\text { - } \quad \text { Os conjuntos climáticos da Terra } \\
\text { - Os climas da Brasil }\end{array}$ \\
\hline $\begin{array}{l}\text { 8: A dinâmica } \\
\text { hidrológica e } \\
\text { as águas conti- } \\
\text { nentais }\end{array}$ & 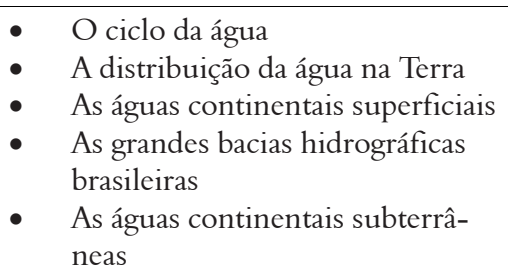 \\
\hline $\begin{array}{l}\text { 9: A água dos } \\
\text { oceanos }\end{array}$ & $\begin{array}{ll}\text { - } & \text { Salinidade e temperatura } \\
\text { - } & \text { Movimentos das águas oceânicas } \\
\text { - } & \text { As correntes marítimas }\end{array}$ \\
\hline $\begin{array}{l}\text { 10: A dinâmica } \\
\text { terrestre }\end{array}$ & $\begin{array}{l}\text { - A litosfera e a estrutura interna } \\
\text { da Terra } \\
\text { - As forças endógenas e a dinâmica } \\
\text { interna do planeta } \\
\text { A tectônica de placas e as trans- } \\
\text { formações na crosta terrestre } \\
\text { Zonas de divergência e conver- } \\
\text { gência da Terra } \\
\text { - Vulcões, terremotos e tsunamis } \\
\text { - A atividade tectônica no Brasil } \\
\text { As forças exógenas da Terra }\end{array}$ \\
\hline $\begin{array}{l}\text { 11: A compo- } \\
\text { sição da crosta } \\
\text { terrestre }\end{array}$ & $\begin{array}{l}\text { - } \quad \text { O ciclo das rochas } \\
\text { - } \quad \text { As solos } \\
\text { - da Trandes estruturas geológicas } \\
\text { - } \quad \text { As paisagens e as formas de relevo } \\
\text { - As formas do relevo brasileiro }\end{array}$ \\
\hline $\begin{array}{l}\text { 12: A interde- } \\
\text { pendência dos } \\
\text { elementos da } \\
\text { biosfera }\end{array}$ & $\begin{array}{l}\text { As grandes paisagens naturais } \\
\text { brasileiras } \\
\text { A transformação dos domínios } \\
\text { morfoclimáticos brasileiros }\end{array}$ \\
\hline
\end{tabular}


trocas de energia e matéria. Christofoletti (1979) afirma que a topografia, os solos e a vegetação preenchem os requisitos para a conformação de um geossistema; ressalta, sobretudo, a relevância do clima como fator preponderante e fornecedor de água e calor (matéria e energia, respectivamente) e que aciona o funcionamento dos elementos da superfície terrestre.

Os autores dos textos didáticos evocam essa teoria para explicar e delinear os contornos das interações dos elementos terrestres que recebem destaque. Os excertos abaixo exemplificam enunciados de alguns textos didáticos de Boligian \& Alves (2013), nos quais é possível identificar a filiação teórica.

(1) "Ainda que os elementos da natureza sejam estudados como partes pertencentes às diferentes esferas terrestres, devemos entender que eles são interdependentes, ou seja, mantém ligações muito estreitas entre si” (Boligian \& Alves, 2013, p. 54).

(2) "As características climáticas de uma região são influenciadas diretamente por fatores como: localização em relação às zonas térmicas da Terra, as massas de ar dominantes e os ventos predominantes" (Boligian \& Alves, 2013, p. 76).

(3) "Para compreendermos a relevância desse elemento primordial (água), é necessário que conheçamos, também, sua dinâmica na natureza e a interdependência que a hidrosfera mantém com as demais esferas terrestres" (Boligian \& Alves, 2013, p. 92).

(4) "Assim como os ventos e as massas de ar, o ciclo da água é movido pela energia solar" (Boligian \& Alves, 2013, p. 93).

(5) "Observe também a interdependência que (a água) mantém com elementos das paisagens naturais e culturais" (Boligian \& Alves 2013, p. 93).

Como exposto nos excertos acima, a presença das palavras "interdependentes" (1), "interdependência” (3) e (5), materializam a filiação do discurso a determinado pensamento científico que concebe a natureza como sistema interdependente. Podemos dizer que o texto didático está explicitamente atre- lado ao discurso que determina o caráter de relação da realidade natural. A representação da natureza é construída discursivamente.

Identificamos que, nestes mesmos excertos, há o que se chama de "intertextualidade manifesta", que figura o caráter polifônico do texto, pois expressa claramente a presença do discurso sistêmico, que é uma concepção científica para estabelecer relações entre componentes da natureza, ao qual os textos mantêm relação de concordância.

A "intertextualidade manifesta", segundo Fairclough (2016), é a presença de outros textos em um texto, ou seja, a presença de uma ou mais vozes possíveis de serem identificadas. As marcações na superfície dos textos estão evidenciadas pelas palavras "interdependentes" e "interdependência" que fazem alusão ao caráter de relação entre a água e outras estruturas terrestres, circunscritas no mesmo campo semântico.

Nos excertos (2) e (4) não há marcas textuais claras que evidenciam a presença explícita de alguma voz, o que nos leva a identificar como "intertextualidade constitutiva" ou "interdiscursividade", de acordo com Fairclough (2016), que é uma forma particular de representar o discurso de outrem no momento da enunciação. O locutor 'toma' o discurso de outrem como seu sem mencionar a voz do enunciador do discurso citado. Assim, nos excertos (2) e (4) os textos apresentam os elementos como dependentes ou em estreita relação uns com os outros, o que engendra o efeito de sentido de interdependência mostrada nos excertos (1), (3) e (5); isso implica dizer que esses dois exemplos últimos estão no mesmo campo de formação discursiva.

Ainda sobre o aspecto da "interdiscursividade" nos textos sobre os processos dinâmicos que formam as paisagens terrestres, esses textos são fundamentados no discurso científico. A presença desse discurso, ora explícito ora implícito, autoriza os produtores dos textos a descreverem os fenômenos e processos naturais como se fossem suas próprias vozes. O discurso científico concebe e constrói a forma pela qual a natureza deve ser figurada discursivamente para ser compreendida por quem ler o texto, assim possibilita raciocínios de relação entre variáveis.

A identificação de profissionais (paleontólogos, historiadores e geólogos) e verbos (investigam, estudam e identificam), que figuram atividades específicas do ambiente científico, garantem a veracidade das informações. Vejamos alguns exemplos de como o discurso científico figura na Unidade 3 
"O tempo da natureza e as marcas das paisagens".

(6) "Para que se fosse possível o estudo do tempo geológico, ou seja, das diferentes fases da história da Terra, especialistas estabeleceram uma escala temporal que distingue os períodos de ocorrência dos eventos naturais" (Boligian \& Alves 2013, p. 47).

(7) Os paleontólogos e os geólogos [...] investigam a origem, a formação das paisagens terrestres, sobretudo pelo estudo dos fósseis de animais e vegetais [...]. [...] os arqueólogos, os antropólogos e os historiadores, estudam a origem e a evolução da espécie humana [...]. Os cientistas conseguem identificar as características de espécies de animais e vegetais [...]. (Boligian \& Alves, 2013, p. 51).

O discurso científico está mesclado no texto principalmente para identificar e explicar o tempo da natureza que identificamos se tratar de "intertextualidade encaixada". "Um texto ou tipo de discurso está claramente contido na matriz de outro" (Fairclough, 2016, p. 158). Nos excertos (8) e (9) os conceitos que são apresentados são do discurso científico, ou seja, elaborados por especialistas que estudam os fenômenos naturais e que foram contextualizados para fins didáticos.

(8) "Os tornados são também sistemas de baixa pressão atmosférica, porém de dimensões bem menores que as de um furacão" (Boligian \& Alves 2013, p. 69).

(9) "Denomina-se pressão atmosférica o peso que a atmosfera exerce sobre a superfície terrestre" (Boligian \& Alves 2013, p. 65).

O discurso científico figura de forma menos
(10) "No que se refere à altitude, quanto mais alto é o lugar em relação ao nível do mar, mais rarefeito é o ar atmosférico [...]" (Boligian \& Alves, 2013, p. 65).

(11) "Cada elemento da superfície terrestre absorve e reflete a radiação eletromagnética de acordo com suas características físicas, químicas e biológicas" (Boligian \& Alves, 2013, p. 58).

(12) A diversidade da vida existente na biosfera e as dinâmicas atmosféricas, hidrológica, e litológica estão condicionadas a importantes fatores astronômicos, como a forma da Terra e os movimentos que ela realiza, além da quantidade de energia que recebe do Sol. (Boligian \& Alves, 2013, p. 54).

Conforme os exemplos acima, não há como identificar, a priori, facilmente, se quem produziu os conhecimentos sobre os fenômenos terrestres foram os produtores do texto, ou se esses produtores utilizaram outros textos (científicos) para enunciar as afirmativas. Esse tipo de fenômeno linguístico é comum em textos didáticos, por meio dos quais se apresenta uma única verdade sobre os fenômenos sociais ou naturais abordados.

Cria-se uma realidade única, sem múltiplos olhares sobre o mesmo objeto e produz-se efeitos de verdade. Isso não acontece no campo científico, o qual se encontra em contínuo processo de (des)construção e que o mesmo objeto pode ser estudado por campos distintos da ciência. Se o conhecimento é algo que se constrói sócio historicamente nem sempre harmonioso, por que o texto didático apresenta esses eventos naturais de forma cristalizada?

No Capítulo 3, que tem por título "O tempo da natureza e as marcas nas paisagens", os produtores acessível ao leitor e pode facilmente ser confundido com a voz de quem produz o texto. Os produtores do texto estão sempre em constante remissão a discursos anteriores (Bakhtin 2009). Fairclough (2016: 159) afirma que "textos ou tipos de discursos estão fundidos de forma mais complexa e menos facilmente separável”. Pudemos verificar a manifestação do que este autor chama de "intertextualidade mista". Observemos:
A estação ainda é primavera, mas os dias já se alongam, e o calor e a umidade típicos de verão dominam as paisagens de quase todo o território brasileiro. As exceções são o extremo norte da Amazônia e o sertão nordestino, onde o tempo ainda é de seca e espera. A ausência de neve ou de um inverno gelado faz da primavera tropical brasileira uma festa de começo indefinido e sutil transição para o verão. Enquanto nas zonas temperadas a fauna e a flora parecem explodir de uma vez só e a estação é dominada pelos brotos e flores, aqui a renovação da vida é descompassada, seguindo ao sabor das chuvas, botões em flores escancaradas, frutos verdes e maduros na mesma árvore, cada espécie em seu ritmo próprio.

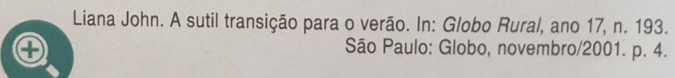

Figura 1. Fragmento de gênero textual que representa o discurso (direto) literário. Fonte: (Boligian \& Alves 2013, p. 46). 
introduzem a temática a partir de discurso direto, na forma de citação; um discurso literário que fora evocado para elucidar a explicação sobre a dinâmica das paisagens brasileiras.

A charge também é utilizada para exemplificar situações do cotidiano no texto didático analisado. $\mathrm{Na}$ figura 2, o personagem animado Garfield está inserido no texto "A previsão do tempo meteorológico".
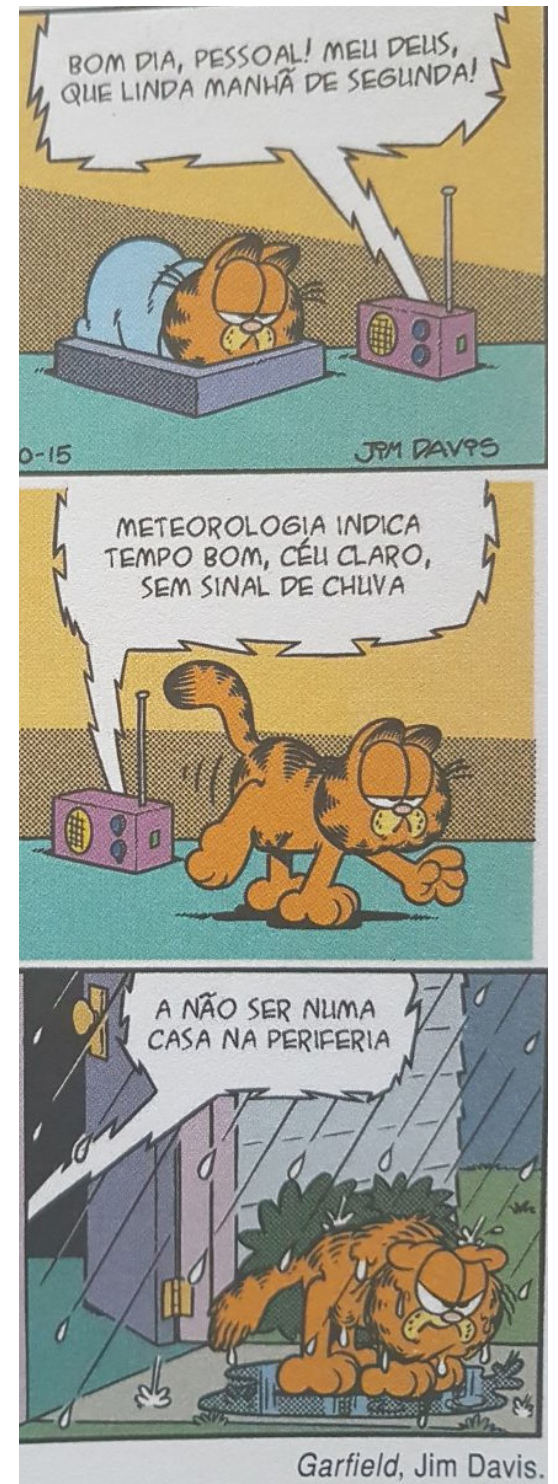

Figura 2. Charge sobre o tempo meteorológico. Fonte: (Boligian \& Alves 2013, p. 73).

O personagem Garfield personifica ações humanas em três imagens. Na primeira cena, deitado, ele escuta a notícia no jornal de que o dia está possivelmente ensolarado em "linda manhã de segunda". Na segunda cena, o personagem sai de casa sem qualquer proteção para a chuva. $\mathrm{Na}$ terceira cena, o personagem encharcado, volta para casa com expressão de desgosto.

A partir das cenas narradas, os produtores do texto tentam, por meio do gênero charge, introduzir o sujeito-leitor nas ações representadas por Garfield; cena esta que não é estranha ao aluno, pois o mesmo pode ter ocorrido em algo momento de sua vida. A charge também assume uma forma de ação lúdico-didática, pois está implícita uma conotação humorística. Acrescentamos que imagens na Análise de Discurso Crítica também são tomadas como discurso, pois são materiais semióticos que engendram determinados significados de representação de aspectos do mundo, das relações sociais, entidades, instituições, pessoas etc (Resende \& Ramalho, 2011).

A figura 2 serve como ilustração do texto que segue, como forma visível e descontraída, representada pelo discurso do humor para elucidar o conteúdo. A natureza que se apresenta na forma de tempo meteorológico, em específico a chuva, recontextualizada com uma possível vivência cotidiano do aluno, busca mobilizar os conhecimentos prévios do leitor para trabalhar a noção de instabilidade/dinâmica da atmosfera.

O discurso do cotidiano também se faz presente na superfície do texto didático. Seja com caráter contextualizador, ao trazer uma situação do dia-a-dia, seja para exemplificar algum fenômeno natural ocorrido, a sua presença elucida a construção de uma realidade próxima do leitor. O discurso do cotidiano introduz a natureza em seu caráter de vivência próxima, percebida rotineiramente como aspecto que compõe a realidade material do leitor. Vejamos isso na figura 3 numa notícia em discurso direto sobre o tempo meteorológico na cidade de São Paulo retirada do livro de Boligian \& Alves (2013).

Podemos dizer que ocorre uma hibridização de discursos: a notícia que segue as informações sobre São Paulo corresponde ao gênero notícia (discurso midiático); e como a fonte se trata de um site de previsão do tempo, é uma informação de utilidade pública, ressignificada como conhecimento didático.

Como afirmado anteriormente, a natureza nesses casos é colocada em seu caráter de proximidade, vivida, sentida pelo leitor. Afirmamos que no início da Unidade II do livro didático, a natureza está figurada em caráter de imprevisão, o que causa 


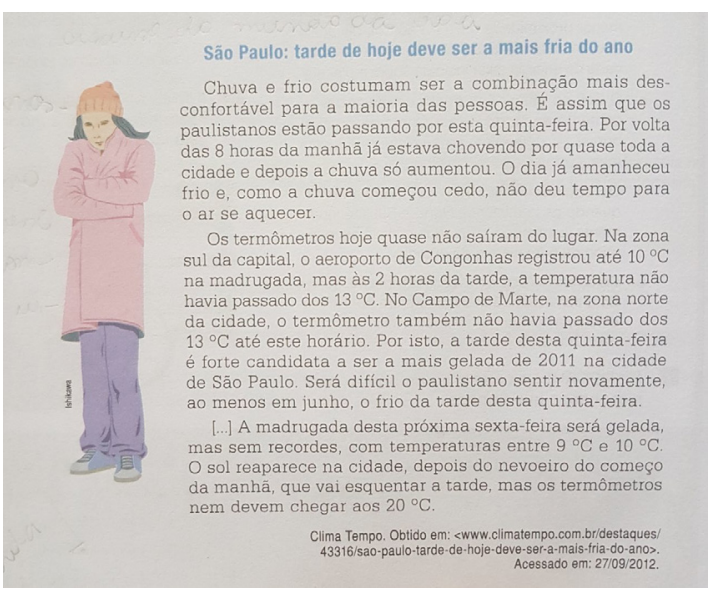

Figura 3. Emprego do discurso do cotidiano em texto didático. Fonte: (Boligian \& Alves 2013, p. 62)

certo efeito de sentido de grandeza, a partir da cena enunciativa criada, fato este comprovado por duas imagens que compõem a introdução: a de um vulcão em atividade (invencibilidade) e outra da aurora boreal (intocável, por estar em elevada altitude).

Quando os produtores apresentam situações que envolvem a natureza vivida no espaço da cidade como na figura 3 e uma situação corriqueira na figura 2, constituem o sujeito leitor para entender a natureza a partir de sua realidade, colocando-o dentro dessas cenas, ao possibilitar alusões aos sentidos em momentos de frio ou de chuva, a partir de seus conhecimentos prévios sobre o comportamento do tempo meteorológico.

O diálogo que se estabelece entre texto e leitor é construído pelo discurso do cotidiano. Os sentidos produzidos sobre os conhecimentos a respeito da natureza se estabelecem pela mediação de conhecimentos prévios que são mobilizados pelos alunos, ao possibilitar inferências sobre o tempo meteorológico. "Antes mesmo de falar, o locutor altera, "modula" sua fala, seu modo de dizer, de acordo com a "linguagem presumida" que cria interlocutores típicos, ou seja, representativos, do grupo a que se dirige" (Sobral, 2009, p. 39). Essa modulação ou adaptação do discurso que os locutores fazem, leva o leitor-aluno e suas práticas espaciais para dentro da cena enunciativa sobre o fenômeno meteorológico, para torná-lo mais compreensível.

Num outro viés, para se analisar os livros didáticos se torna importante abordar a questão do desenvolvimento tecnológico e das técnicas no mundo moderno. O desenvolvimento tecnológico tem acumulado ano após anos, um conjunto de dispositivos que tem sido popularizado. A partir disso, a técnica tem estado cada vez mais presente no cotidiano das pessoas. Os recursos tecnológicos estão sendo utilizados para planejamento de viagens, passeios, atividades econômicas, etc., com as mais diversas finalidades. Essa introdução da técnica no cotidiano das pessoas está presente em alguns textos analisados. As pessoas comuns programam suas atividades a partir do momento em que têm acesso a determinados 'controles tecnológicos' de monitoramento da natureza. Vejamos isso em alguns trechos no texto "Será que vai ter onda?".

(13) "Basta um computador para saber o nível do mar em qualquer parte do mundo, e as informações das boias náuticas não são mais exclusividade da Marinha e de militar e pescador" (Boligian \& Alves 2013, p. 113).

(14) "O passeio virtual e as informações trazem precisão para o surfista que está longe do litoral” (Boligian \& Alves 2013, p. 113).

(15) "Com um ou dois cliques, é possível saber se o swell aumentará, se o vento diminuirá, se a ondulação mudará de direção" (Boligian \& Alves 2013, p. 113).

O excerto (13) exemplifica o caráter democrático de socialização dos conhecimentos sobre a natureza para uma pessoa comum, um surfista. Ainda neste excerto, podemos inferir também que há domínio privado dos conhecimentos técnicos ao mencionar que o domínio militar tem sido apropriado pelo domínio público - o surfista, ou qualquer outra pessoa que tenha curiosidade sobre o tema.

Nos excertos (13), (14) e (15) também se verificam a relação de "desencaixe" entre tempo e espaço nos termos de Giddens (1991) a partir dos ‘sistemas perito'.

\begin{abstract}
"Os sistemas peritos são mecanismos de desencaixe, porque [...] eles removem as relações sociais das imediações do contexto. [...] pressupõem, embora também promovam, a separação entre tempo e espaço como condição do distanciamento tempo-espaço que eles realizam" (Giddens, 1991, p. 139).
\end{abstract}

Desta forma, não há mais necessidade da presença física nos lugares para estabelecer relações sociais ou tomar conhecimento em tempo real de determinadas partes do globo. Entretanto, é inte- 
ressante que o texto realiza um contraponto sobre a questão da interação com o outro, ao afirmar que, para o turista, o interessante é viver a sensação de subir no morro e conversar com os pares sobre as condições do tempo e das marés. Isso está explícito no excerto (16).

(16) Chegar pela internet vale a pena, mas subir no morro, sentir a força do vento e discutir com colegas as condições são os maiores exercícios para ofeeling do surfista, além de mais prazerosos do que ficar diante do computador (Boligian \& Alves 2013, p. 113).

O capítulo 11 tem por tema "A composição da crosta da terrestre". O texto abre para uma abordagem econômica das rochas, seu valor de uso para a utilização em atividades produtivas. Agrega a essa utilização da natureza impactos consideráveis no ambiente. Em seguida, em outro subtópico, aborda a questão da produção brasileira de minérios. A natureza está reduzida ao seu potencial de ser (utilizável) em atividades-fim. Prevalece o discurso da exaltação das riquezas naturais distribuídas pelo território nacional.

(17) "O Brasil apresenta uma das mais variadas reservas de minérios do mundo, fato que deve à extensão e à composição litológica do território nacional” (Boligian \& Alves 2013, p. 137).

Os sentidos potenciais de natureza atestam para formas particulares de concebê-la. Assim, a natureza se materializa na forma de "jazidas", "reservas" de riqueza expressa na forma de minérios, de elementos químicos que possuem valor econômico.
O texto se filia ao discurso do "conhecer (a natureza) para ter", discurso da sustentabilidade. A sustentabilidade evocada para declarar o cuidado com a natureza. Os solos representam uma variável natural com alta fragilidade ambiental, segundo o texto.

O capítulo 12 intitulado "A interdependência dos elementos na biosfera" fecha o ciclo de conteúdos restritos aos aspectos naturais. Encerra o discurso de representações sobre a natureza. Apresenta os biomas terrestres como paisagens de interação e circunscreve seis. Os enunciados foram organizados para criar uma cena ampla do aspecto terrestre desses sistemas ambientais, com isso, mapas, gráficos e textos curtos afirmam, representam, corroboram e informam sobre cada bioma.

Depois da abordagem global dos fenômenos, os locutores fazem um recorte em escala nacional (no caso o do Brasil) e apresentam o que foi classificado por Aziz Ab'Saber como Domínios Morfoclimáticos - imagem 4. Tanto o texto quanto a imagem persistem na descrição dos domínios. A natureza descritiva de conteúdos sobre aspectos físicos atesta para uma aprendizagem mnemônica, ou seja, de memorização. É a retomada de uma memória discursiva que não apresenta os processos de transformação pelos quais essas paisagens têm passado.

Ressaltamos que a memorização faz parte do processo de ensino e aprendizagem, mas não deve ser o suficiente para abordar este tema. Com isso, se constrói duas posições de sujeitos: aquele que descreve as paisagens e outro que apenas contempla as descrições. Consequentemente, os produtores do texto deixam de utilizar o tema para ganho na aprendizagem, como possibilidade de exploração e investigação de conhecimento e promoção de um saber

O ciclo das rochas se reduz a uma imagem explicativa, a qual sucintamente explica a formação das rochas magmáticas, metamórficas e sedimentares.

Sobre o tema solos, os enunciadores o atrelam à vida presente na biosfera. O texto se cerca do discurso da cautela quanto ao uso. Assim, a natureza representada no solo figura como algo frágil que precisa de cuidados, principalmente para o uso deste recurso natural por futuras gerações, revelando filiação ao discurso ambiental sobre esse sistema.

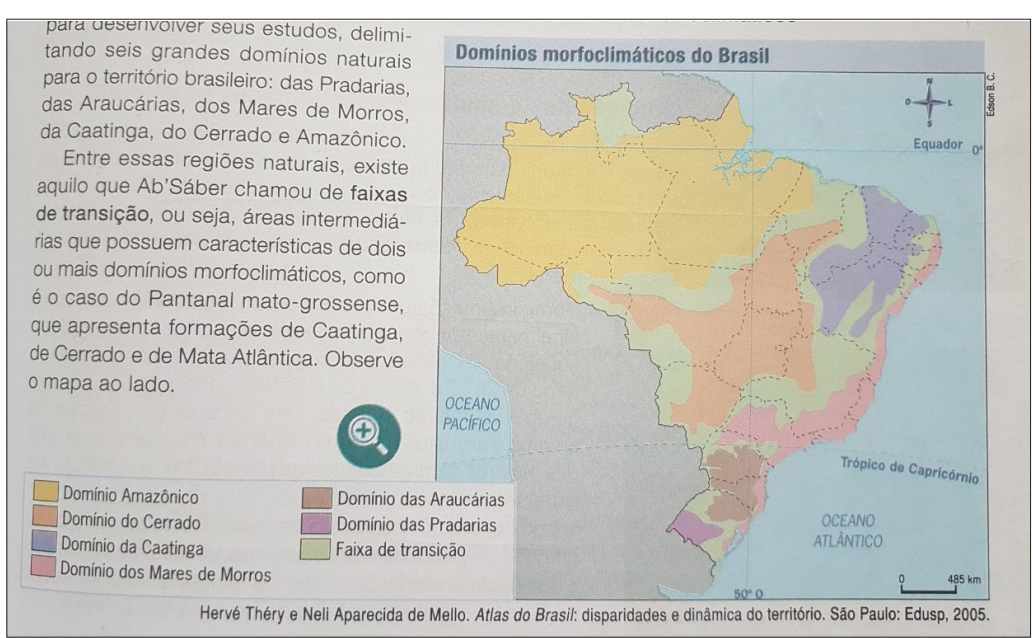

Figura 4. Representação dos Domínios Morfoclimáticos. Fonte: Boligian \& Alves (2013, p. 155). 
(natural) importante dentro da geografia escolar.

O agente (grupos sociais ou empresariais, entidades, corporações etc) que modifica o ambiente é ocultado ou dissimulado da superfície do texto, a partir da construção de enunciados em voz passiva que deixa o discurso com ethos generalista, quando se trata de abordar as modificações feitas no ambiente. Segundo Fairclough (2016) a transformação de um enunciado para a voz passiva pode dissimular o agente da ação porque ele já é conhecido, desconhecido, julgado irrelevante, o que pode retirar o peso da responsabilidade. Além disso, o texto não problematiza quais modificações foram efetuadas, tampouco identifica quem alterou e onde exatamente. Vejamos.

(18) "Atualmente, grande parte dos domínios morfoclimáticos localizados nas regiões mais intensamente ocupadas [...] encontra-se bastante alterada ou completamente devastada pela ação humana" (Boligian \& Alves 2013, p. 156).

Em alguns casos há a apresentação das atividades econômicas como responsáveis pela devastação causada: no domínio amazônico, "grandes propriedades rurais"; na Caatinga a "pecuária bovina"; no Cerrado, "instalações agropecuárias"; no domínio dos Mares de Morros, os sujeitos do passado atestam para o processo de alterações realizadas, identificados apenas como "portugueses" e precursores; nas Araucárias, pela "fabricação de móveis" e pela "construção civil”. Agentes, processos e formas são silenciados, o que evidencia um espaço sem conflitos, diferentemente de pesquisas científicas e das notícias de jornais e revistas. Vejamos os enunciados sob o predomínio da voz passiva nos excertos abaixo e como constroem sentidos potenciais de um discurso generalista.

\section{Sobre o Domínio amazônico:}

(19) “[...] esse domínio natural vem sendo devastado nas últimas décadas devido ao avanço das grandes propriedades rurais, das madeireiras, dos garimpos e dos núcleos de povoamento" (Boligian \& Alves 2013, p. 156).

\section{Sobre o Domínio da Caatinga:}

(20) "Essa área sofre alterações desde a época do Brasil Colônia, quando passou a ser utilizada para o desenvolvimento da pecuária bovina no Nordeste" (Boligian \& Alves 2013, p. 157).
Sobre o Domínio do Cerrado:

(21) "Nas últimas décadas, o Cerrado tem sido intensamente alterado para dar lugar a áreas de pastagem (para a criação de gado) e para a instalação de lavouras (sobretudo a cultura da soja)" (Boligian \& Alves 2013, p. 157).

Sobre o Domínio dos Mares de Morros:

(22) "A vegetação original é a floresta tropical, mais conhecida como Mata Atlântica, que desde o aportamento inicial dos portugueses, no século XVI, vem sendo devastada de forma ininterrupta" (Boligian \& Alves 2013, p. 157).

Sobre o Domínio das Pradarias:

(23) "Atualmente, boa parte das pradarias encontra-se alterada devido, sobretudo, à prática secular da criação extensiva de gado e, mais recentemente, à introdução das culturas de arroz e trigo" (Boligian \& Alves 2013, p. 158).

Se nos atentarmos mais de perto para as marcações que inscrevem essas atividades acima aludidas, são todas parte de um mesmo sistema econômico: o sistema capitalista, o que evidencia que o capital, aplicado sob diversas maneiras e figurado recorrentemente em textos didáticos é tomado como tácito, algo dado porque aí está, então só caberia descrevê-lo. Relatar suas ações sobre um espaço que se transforma na contradição que é excluída da superfície do texto. A contextualização socioespacial do uso dos recursos naturais, pertencentes aos Domínios Morfoclimáticos, não é explorada e isso poderia ser feito para situar esses Domínios no contexto da ciência geográfica atual.

Carlos (2012) aponta dois movimentos que fundam a produção social do espaço em sua contradição, quais sejam, um que se baseia em alianças político-econômicas impostas por uma racionalidade técnica e, outra, que o espaço se torna condição, meio e produto para o desenvolvimento da vida social. O texto didático não apresenta nem um movimento nem outro, se apresenta como uma história construída que está aí para ser narrada sem a presença dos sujeitos.

O texto desenvolve-se a partir de alguns recursos tais como as "pressuposições" que atestam para uma intertextualidade que não é fácil de ser identificada. "Pressuposições são proposições que são tomadas pelo(a) produtor(a) do texto como 
já estabelecidas ou 'dadas' [...] e há várias pistas formais na organização de superfície do texto para mostrar isso" (Fairclough, 2016, p. 161).

Pudemos identificar a contradição no discurso do texto a partir da comparação da imagem 4, que representa um discurso específico anterior (o da não alteração, ou seja, da natureza em si), por meio das marcações textuais que atestam para tais modificações nesses ambientes. $O$ texto formula duas representações: uma da natureza intocada e outra da natureza transformada, mas o que realmente acontece no território, como afirmamos anteriormente, a ausência do conflito e das intenções dos sujeitos, são dissimuladas.

A explanação das características naturais dos domínios morfoclimáticos em primeiro plano na oração, o que (Fairclough 2016) chama de "tema" coloca em evidência o que os produtores de textos querem apresentar, que são os aspectos físicos gerais e não as modificações antrópicas que são o "rema", ou seja, informações que se encontram segundo plano, que neste caso traz em si uma generalização opaca dessas modificações. O texto se filia mais a um discurso do 'natural' do que para a ação antrópica em si, enfatizando uma memória discursiva dos séculos XIX e século XX: a descrição, localização e memorização das paisagens naturais do mundo e do território nacional.

O texto não apresenta quais são as formas espaciais que residem nesses domínios, apenas se pode identificar que se tratam de atividades desenvolvidas no campo (atividades agropecuárias, de extração mineral ou vegetal etc.). É um outro espaço que se apresenta. O texto também perde por não produzir sentidos críticos, quando descreve de forma geral as atividades antrópicas sem uma construção sóciohistórica desses ambientes.

A utilização de um mapa atual que apresentasse o grau de alteração dessas paisagens poderia ser de suma importância para construir os sentidos acerca da produção do espaço, ou pelo menos dar visibilidade a essa questão. Isso poderia aludir o caráter dinâmico de como o território nacional fora construído, a partir da utilização da própria natureza. Neste sentido, os conhecimentos dos Domínios Morfoclimáticos seriam imprescindíveis para entender as formas pelas quais se levou a utilização dessas áreas no desenvolvimento de atividades específicas, e, assim, mostrariam, com mais clareza como se dá a relação entre a sociedade contemporânea brasileira e a natureza.

\section{Considerações Finais}

Buscamos neste trabalho identificar e analisar os discursos que embasam os textos didáticos sobre a natureza (por meio dos conteúdos da Geografia Física) nos livros didáticos de Geografia, a qual é figurada de diversas formas. Os textos apresentam representações discursivas que refletem momentos históricos diferentes.

Os textos escolares investigados apresentam também novos olhares sobre a natureza, a partir da teoria geossistêmica que identifica, classifica e atribui aos determinados elementos terrestres funções específicas de (des)construção das paisagens terrestres, a natureza é discursivamente apresentada por processos. Isso representa uma mudança discursiva de como os conteúdos da Geografia Física pode ser figurada em textos didáticos.

Identificamos múltiplas vozes que constroem os textos didáticos como, por exemplo, o discurso do cotidiano, do mundo da vida, por meio do qual a natureza é posta a ser conhecida, pelo homem comum, com a popularização dos conhecimentos científicos. Esses textos abrem possibilidades de novas leituras e debates na sala de aula, sobre os conhecimentos da natureza nos dias atuais, ao introduzir o elemento tecnologia.

A modulação discursiva, por meio da introdução de situações cotidianas que representam a relação homem/meio, exercida por meio do texto, proporcionam ao aluno um entendimento mais próximo dos fenômenos atmosféricos. Ao relacionar uma informação a partir do gênero notícia, em discurso direto, criando efeito de proximidade entre a cena da enunciação e o leitor, ajuda na construção de nexos de aprendizagem. Essa construção é feita a partir da mobilização de conhecimentos prévios.

Como se trata de discurso, as 'permissões' do ato de enunciar no livro didático devem ser compreendidas a partir da sombra do discurso institucional, pois este material tem lugar situado para existir. Portanto, passa pelo "crivo" da inclusão e exclusão de conteúdos que atendam a determinados projetos educacionais (governamentais).

Alguns textos apresentam permanências, principalmente quando se trata dos conteúdos que são atravessados pelo discurso econômico, o qual permite que não sejam enunciados um outro espaço que não seja o espaço do e para o capital. Essas permanências aparecem quando se trata dos conteúdos sobre a litosfera. 
Nas análises apresentadas foi possível perceber que os textos didáticos não são simples reduções da ciência geográfica. Dito de outra forma, não são versões simplificadas da Geografia Física, mas sobretudo, são formas particulares de conceber tais conhecimentos. A análise das palavras e sua força nos enunciados, nas permanências e nas mudanças discursivas, como postula Fairclough (2016), torna-se rica fonte de novas compreensões do motivo pelo qual a natureza figura de maneira tal, e as motivações por ter sido de tal maneira dissimulada, além dos papéis que tem desempenhado para o homem na produção do espaço.

\section{Referências}

Albuquerque, M. A. M. de. (2011). Livros didáticos e currículos de geografia, pesquisas e usos: uma história a ser contada. In Tonini I.M. (Ed.). (2011). O ensino de geografia e suas composições curriculares (pp. 155-168). Porto Alegre: UFRGS

Bakhtin, M. (2009). Marxismo e filosofia da linguagem: problemas fundamentais do método sociológico na ciência da linguagem. São Paulo: Hucitec

Barbosa, T. (2006). O conceito de natureza e análises dos livros didáticos de geografia. (Dissertação de Mestrado). Presidente Prudente: Universidade Estadual Paulista.

Boligian, L., Alves, A. (2013). Geografia, espaço e vivência. São Paulo: Saraiva.
Carlos, A. F. A. (2012). Da "organização" à "produção" do espaço no movimento do pensamento geográfico. In Souza M. L. de, Sposito, M. E. B. (Eds.) (2012). A produção do espaço urbano: agentes e processos, escalas e desafios (pp. 53-73). São Paulo: Contexto.

Cassiano, C. C. F. (2007). O mercado do livro didático no Brasil. (Tese de Doutorado). São Paulo: Pontifícia Universidade Católica.

Christofoletti, A. (1979). Análise de sistemas em Geografia. São Paulo: Editora Hucitec.

Fairclough, N. (2016). Discurso e mudança social. Brasília, DF: UnB.

Giddens, A. (1991). As consequências da modernidade. São Paulo: Ed. Unesp.

Maingueneau, D. (2005). Gênese dos discursos. Curitiba: Criar.

Maingueneau, D. (2015). Discurso e análise do discurso. São Paulo: Parábola.

Maingueneau, D. (2013). Análise de texto de comunicação. São Paulo: Cortez.

Resende, V. de M., Ramalho, V. (2011). Análise de discurso (para a) crítica: o texto como material de pesquisa. Campinas, São Paulo: Pontes Editores.

Sobral, A. U. (2009). Do dialogismo ao gênero: as bases do pensamento do círculo de Bakhtin. Campinas, SP: Mercado de Letras.

Tonini, I. M. (2011). Livro didático: textualidades em redes? In Tonini, I. M. (Ed.). (2011). O ensino de geografia e suas composições curriculares (pp. 145-154). Porto Alegre: Ed. UFRGS. 